\title{
Kinematics and strain analyses of the eastern segment of the Pernicana Fault (Mt. Etna, Italy) derived from geodetic techniques (1997-2005)
}

\author{
Mimmo Palano, Marco Aloisi, Mauro Amore, Alessandro Bonforte, Francesco Calvagna, \\ Massimo Cantarero, Orazio Consoli, Salvatore Consoli, Francesco Guglielmino, \\ Mario Mattia, Biagio Puglisi and Giuseppe Puglisi \\ Istituto Nazionale di Geofisica e Vulcanologia, Sezione di Catania, Italy
}

\begin{abstract}
This paper analyses the ground deformations occurring on the eastern part of the Pernicana Fault from 1997 to 2005. This segment of the fault was monitored with three local networks based on GPS and EDM techniques. More than seventy GPS and EDM surveys were carried out during the considered period, in order to achieve a higher temporal detail of ground deformation affecting the structure. We report the comparisons among GPS and EDM surveys in terms of absolute horizontal displacements of each GPS benchmark and in terms of strain parameters for each GPS and EDM network. Ground deformation measurements detected a continuous left-lateral movement of the Pernicana Fault. We conclude that, on the easternmost part of the Pernicana Fault, where it branches out into two segments, the deformation is transferred entirely SE-wards by a splay fault.
\end{abstract}

Key words GPS - EDM - ground deformation Pernicana Fault - Mt. Etna

\section{Introduction}

In recent literature on Mt. Etna, the Pernicana fault system is described as one of the most active structures in the geodynamic framework of the volcano (Borgia et al., 1992; Lo Giudice and Rasà, 1992; Azzaro et al., 2001; Obrizzo et al., 2001; Acocella et al., 2003). Models proposing flank sliding (e.g., Borgia et al., 1992; Lo

Mailing address: Dr. Giuseppe Puglisi, Istituto Nazionale di Geofisica e Vulcanologia, Sezione di Catania, P.zza Roma 2, 95123 Catania, Italy; e-mail: puglisi-g@ct.ingv.it
Giudice and Rasà, 1992) agree in identifying it as the northern boundary of the volcano's moving flank.

The fault system is formed of discrete segments, arranged in a right stepping en échelon configuration, of a near continuous left-lateral shear zone that dissects the north-eastern flank of Mt. Etna (fig. 1a,b). From West to East, it joints the NE-Rift (1900 m a.s.l.) crossing the Piano Provenzana and Piano Pernicana areas (fig. 1a,b), and reaches Rocca Pignatello (1050 m a.s.l.) and Rocca Campana areas (900 m a.s.l.), where the fault branches out SE-wards into two fault segments (fig. 2). The former shows a roughly $\mathrm{N} 105^{\circ}$ orientation from Rocca Pignatello to Rocca Campana area, here the fault rotates to $\mathrm{N} 90^{\circ}$ and terminates without morphological evidence; the latter propagates downhill from Rocca Campana area with a roughly $\mathrm{N} 120^{\circ}$ orientation. Dur- 


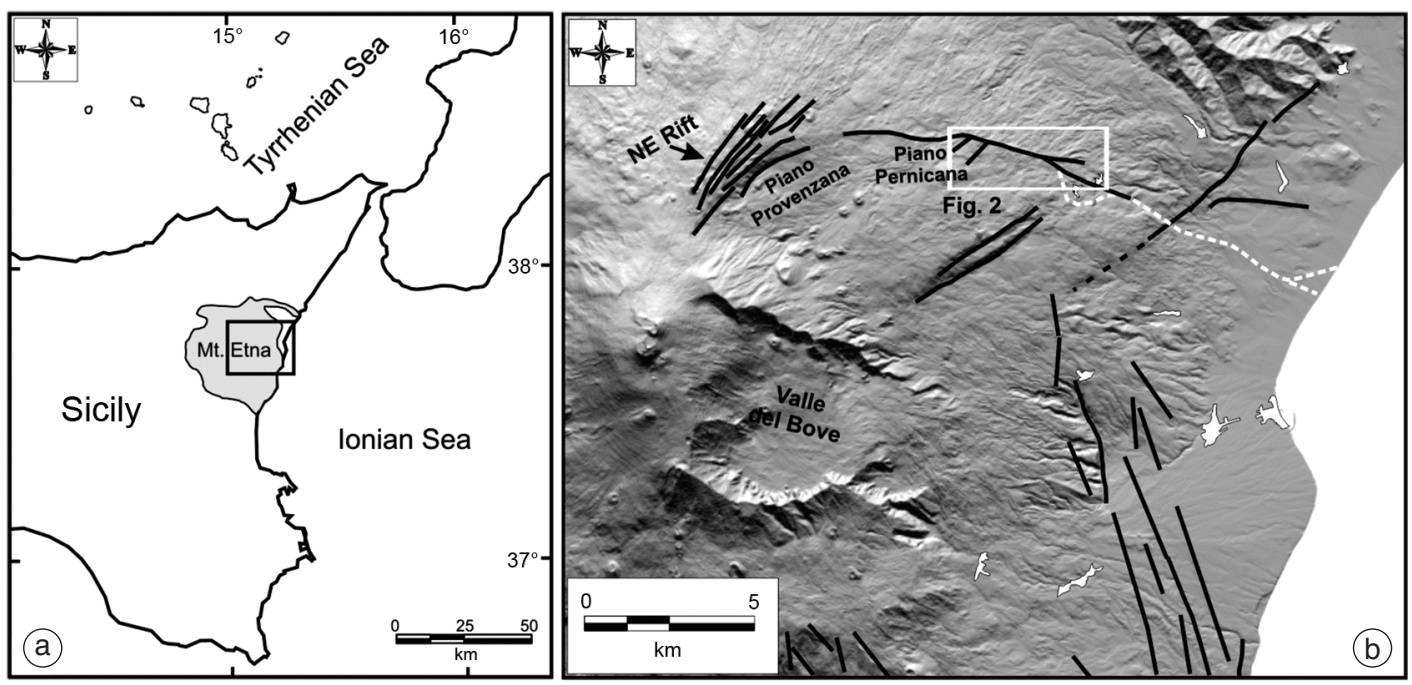

Fig. 1a,b. a) Location and b) tectonic sketch map of the eastern flank of Mt. Etna. White dotted lines indicate the development of the Pernicana Fault splay down to the Ionian coast during the 2002-2003 eruption.

ing the 2002-03 Mt. Etna eruption, a huge ground fracturing phenomena involved the whole north-eastern flank allowing to identify the development of the Pernicana Fault splay down to the Ionian coast (Neri et al., 2004) (fig. 1a,b).

The western and central segments of the fault are seismogenic, with frequent shallow earthquakes, which can reach magnitudes up to 4.2 , and cause severe damage to man-made features and surface faulting (Azzaro et al., 1998). The eastern segment of the fault is characterized by aseismic fault movements with striking evidence of activity revealed by continuous left-lateral displacements having a creep-rate of about $2.8 \mathrm{~cm} / \mathrm{yr}$ based on historic and geodetic estimations (Azzaro et al., 2001).

Recent earthquakes producing large surface fractures and damage to man-made features were recorded on December 25th 1985, October 29th 1986 and September 22nd 2002, respectively with $M=4.0, M=4.1$ and $M=3.7$ (Azzaro et al., 1998; Acocella et al., 2003). During the first days of the 2002-2003 eruption, several earthquakes $\left(M_{\max }=4.0\right)$ occurred on the western and central parts of the Pernicana Fault having strike-slip mechanisms (Barberi et al.,
2004). To date, although no further large earthquakes have occurred, widespread seismicity has characterized the central and western segments of the fault, confirming that the structure is highly active.

During the time interval considered here, the volcanic activity at Mt. Etna was characterized by a series of summit eruptions (July 1997December 2000; Bhencke and Neri, 2003) and by three flank eruptions: July-August 2001, October 2002-January 2003 and September 2003March 2004 (INGV-CT Research Staff, 2001; Andronico et al., 2005; Burton et al., 2005).

This paper analysed the geodetic data acquired by three local geodetic networks (GPS and EDM) installed in 1997 along the eastern segment of the Pernicana Fault (Azzaro et al., 2001).

\section{Geodetic networks and surveys}

In order to adequately survey the Pernicana Fault and provide complementary information on the dynamic of the main fault plane and of the branch fault, two local geodetic networks 


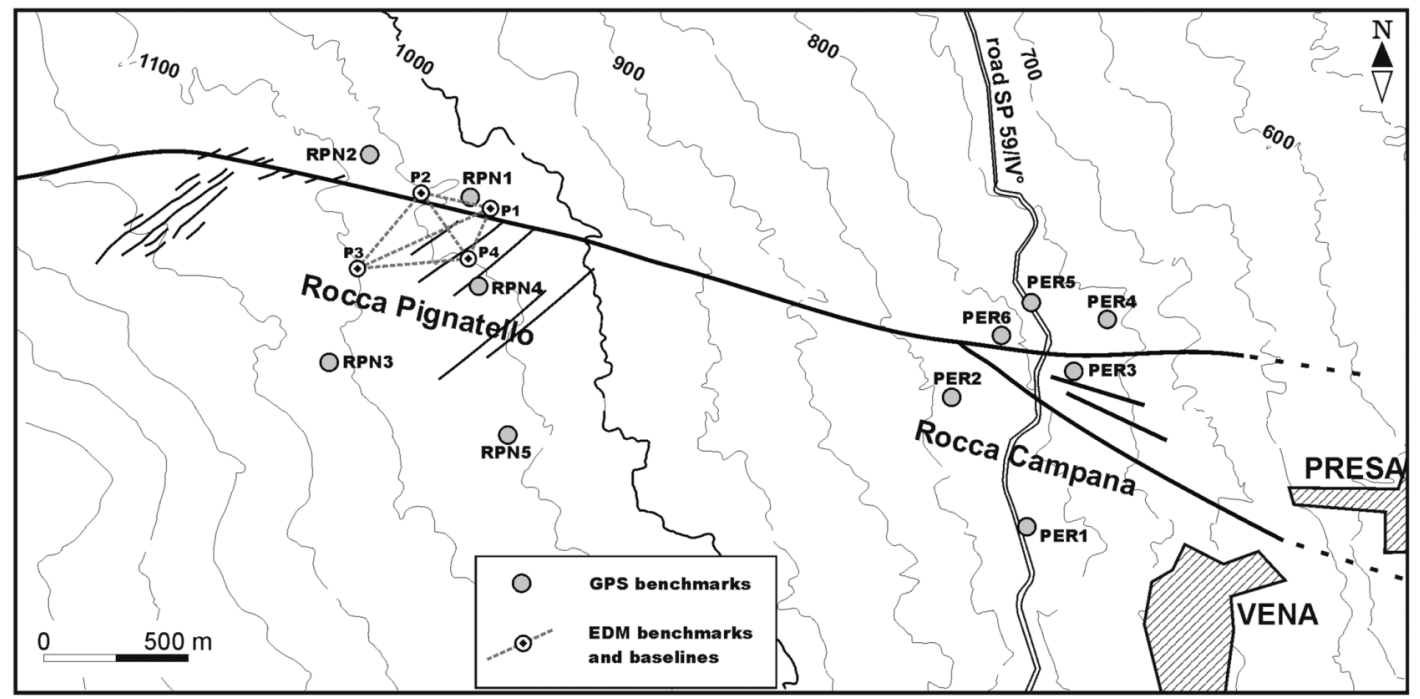

Fig. 2. Configuration of the three geodetic networks used in this paper with respect to the fault: two at Rocca Pignatello (RPN) and one at Rocca Campana (RCN). At Rocca Pignatello the EDM network was measured up to 2002, afterward only the GPS network was surveyed. The eastern segment of the Pernicana Fault and the splay fault are also reported.

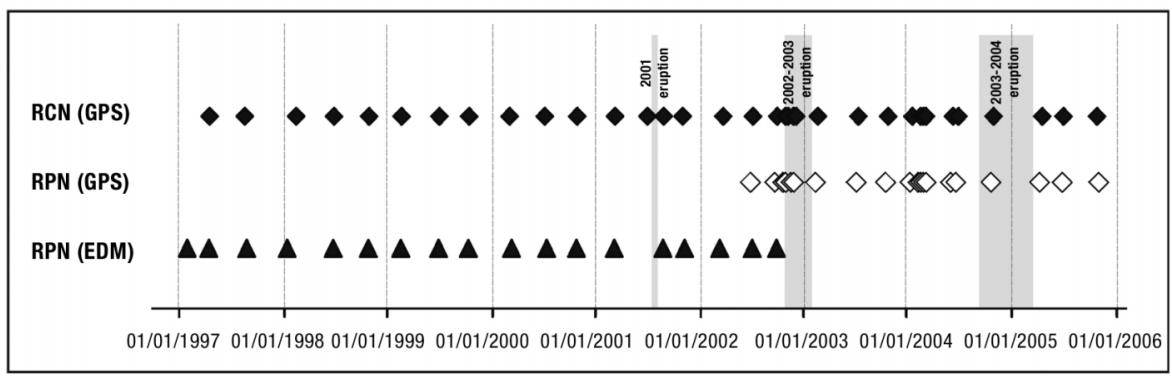

Fig. 3. Chronogram of the surveys carried on the three geodetic networks.

were established by Istituto Internazionale di Vulcanologia in April 1997 across the eastern segment of the structure on «Rocca Pignatello» and «Rocca Campana» areas (Azzaro et al., 2001) (fig. 2).

GPS technique was adopted to survey the Rocca Campana Network (RCN), while EDM technique was adopted to measure the Rocca Pignatello one (RPN). The two networks are relatively small, covering an area in the order of
$1 \mathrm{~km}^{2}$. The number of benchmarks was 6 and 4 respectively. In the case of the GPS network, self-centring benchmarks, similar to those installed for the GPS networks of Mt. Etna (Puglisi et al., 1998), were adopted. In order to upgrade the EDM network, a new GPS network was installed at Rocca Pignatello area in July 2002. This GPS network consists of 5 self-centering benchmarks. The EDM network has not been surveyed since September 2002. 
The first measurements of the networks were carried out in early 1997; then, the networks were surveyed at least three times a year in order to adequately detect pattern and rate variations of ground deformation (fig. 3). The surveys were performed every four months on average except during the 2002-2003 eruption, when almost daily measurements were carried out.

The instrumentation was based on the use of a geodimeter AGA 6000 (accuracy of $1 \mathrm{ppm}$ ) for the EDM network and on the use of Trimble receivers (4000 SSI, 4000 SSE and more recently 4700) and Trimble antennas (Choke Ring and Compact models) for the GPS networks. In the case of the GPS surveys, the session time ranged between 2-4 h, depending on the SV coverage and/or logistic conditions.

\section{Data processing}

In order to provide useful information and to define the evolution of the ground deformation pattern in the investigated area, the geodetic data obtained at different times by the EDM and the GPS surveys must be comparable. The two adopted surveying techniques require different methods to achieve this aim.

The EDM measurements were reduced to ground level (nails) by using appropriate surveying strategies (Azzaro et al., 2001) and the distances are also corrected by using meteorological data simultaneously acquired during the distance measurements at both ends of the measured baseline. Finally, we directly compared the corrected distance measurements of different surveys to obtain the length variations for each baseline.

The GPS data were processed separately for each network and each survey using the Trimble Geomatics Office package v.1.5, produced by Trimble, and precise ephemeredes provided by the International Geodetic Service. The baseline solutions obtained were then adjusted in two steps. First of all, the set of baseline solutions for each network was adjusted according to the hypothesis of the inner constraints (Prescott, 1981); this step allows validating the consistency of the data for each survey. Then each network was fixed to an appropriate reference frame by as- suming an appropriate set of co-ordinates for selected benchmarks. For the surveys considered in this paper, benchmarks PER5 and RPN2 were assumed as the fixed points for the RCN and RPN networks respectively. In such conditions, the consistency of the reference frame among different surveys is achieved through the precise ephemeredes, which guarantee that rotation and scale factors are properly considered in the processing. The final solution consists in a set of the benchmark co-ordinates for each campaign. The averaged accuracy was about $0.2 \mathrm{~cm}$ for the horizontal components and about $0.4 \mathrm{~cm}$ for the vertical one. Finally, the result of each GPS survey was compared to the others, usually the previous one.

The comparison of the surveys allows both the inversion of the strain tensor and the computation of the displacement vectors, depending on the type of available data. In the case of the EDM baseline variations only the strain tensor can be obtained, while both displacement vectors and the strain tensor can be obtained from the GPS comparisons.

\section{Comparison of the results}

\subsection{Analysis of vector displacements}

The comparison of benchmark co-ordinates, obtained from GPS surveys, yields displacement vectors for different time intervals. Then, for each benchmark we analyse the time series of the displacements to acquire the statistics relevant to the motion directions, by using a wind rose diagram. In fig. 4 the frequencies of vector directions are grouped into 36 direction classes (every $10^{\circ}$ of azimuth). Each class is coloured according to the magnitude of the displacement: light grey colour represents small displacements (from 0 to $0.5 \mathrm{~cm}$, which is within the error range), dark grey colour medium displacements (from 0.5 to $2 \mathrm{~cm}$ ) and black colour strong displacements $(>2 \mathrm{~cm})$.

Figure 5a reports the cumulative displacement vectors calculated for the two GPS networks. Due to the different installation time, the vectors relevant to RPN network cannot be compared with those relevant to RCN network. 

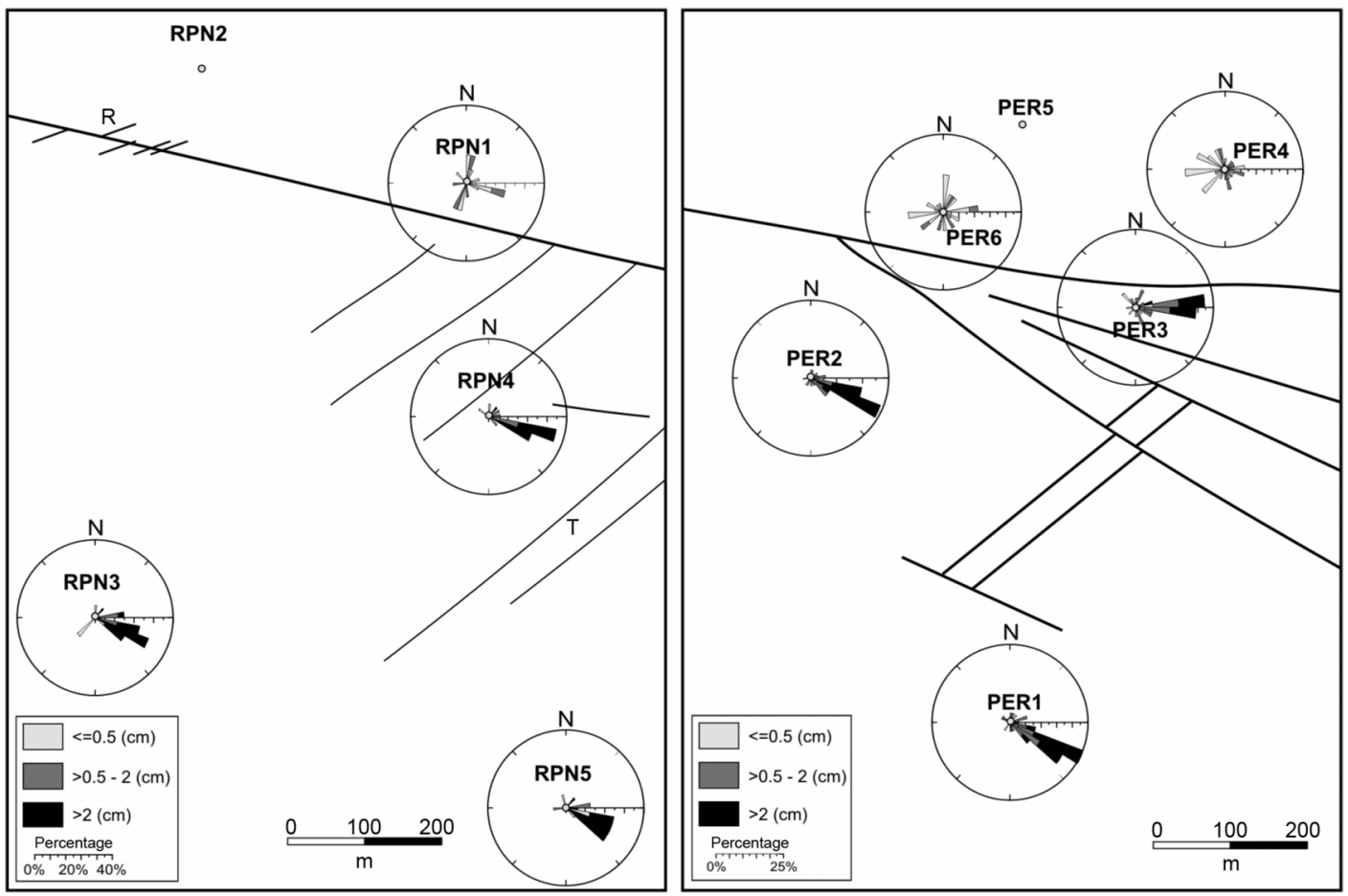

Fig. 4. Wind-rose diagrams relevant to the motion directions for each benchmark. The frequencies of vector directions are grouped to 36 direction classes (every $10^{\circ}$ of azimuth).

Figure $5 b, c$ reports the time evolution of the displacement of some selected benchmarks.

The GPS data provide fundamental information to correctly interpret the kinematics of the fault. The following features of the ground deformation pattern may be pointed out:

a) The evident ESE-ward displacements detected at benchmarks PER1, PER2, RPN3, RPN4 and RPN5 (fig. 5a) highlight the left-lateral kinematics of the fault.

b) At RPN network the ESE-ward displacements detected at benchmarks RPN3, RPN4 and RPN5 have the same magnitude (fig. 5c); this suggests that in this area the ground deformation pattern is due only to the main fault. Instead, at RCN network, the different magnitude of the displacements measured at benchmark PER3 with respect to those measured at benchmarks PER1 and PER2 (fig. 5b) clearly indi- cates the partition effects played by the splay fault $\mathrm{N} 120^{\circ}$-oriented $(\alpha)$, which accommodates more than twice the displacement on the $\operatorname{arm} \beta$ $\mathrm{N} 90^{\circ}$-oriented of the main fault (fig. 5a).

c) The most frequent $(22.5 \%)$ vector azimuths measured at the benchmark PER3 are $\mathrm{N} 80^{\circ} \mathrm{E}-\mathrm{N} 90^{\circ} \mathrm{E}$ (fig. 4 ) indicating a local convergence toward the $\operatorname{arm} \beta$ of the fault. This effect leads to a slight and occasional reverse component on the arm $\beta$ of the main fault, coupled with the major left-lateral motion.

d) The two most frequent directions of displacement measured at benchmark PER2 are $\mathrm{N} 120^{\circ} \mathrm{E}-\mathrm{N} 130^{\circ} \mathrm{E}(24 \%)$ and $\mathrm{N} 110^{\circ}-\mathrm{N} 120^{\circ}(19 \%)$ (fig. 4) indicating a main left lateral kinematics of the splay fault. Furthermore, the $\mathrm{N} 110^{\circ} \mathrm{E}-\mathrm{N} 120^{\circ}$ direction of displacement shows a component towards the splay fault, evidencing a second-order reverse motion also on this fault. Similar behav- 


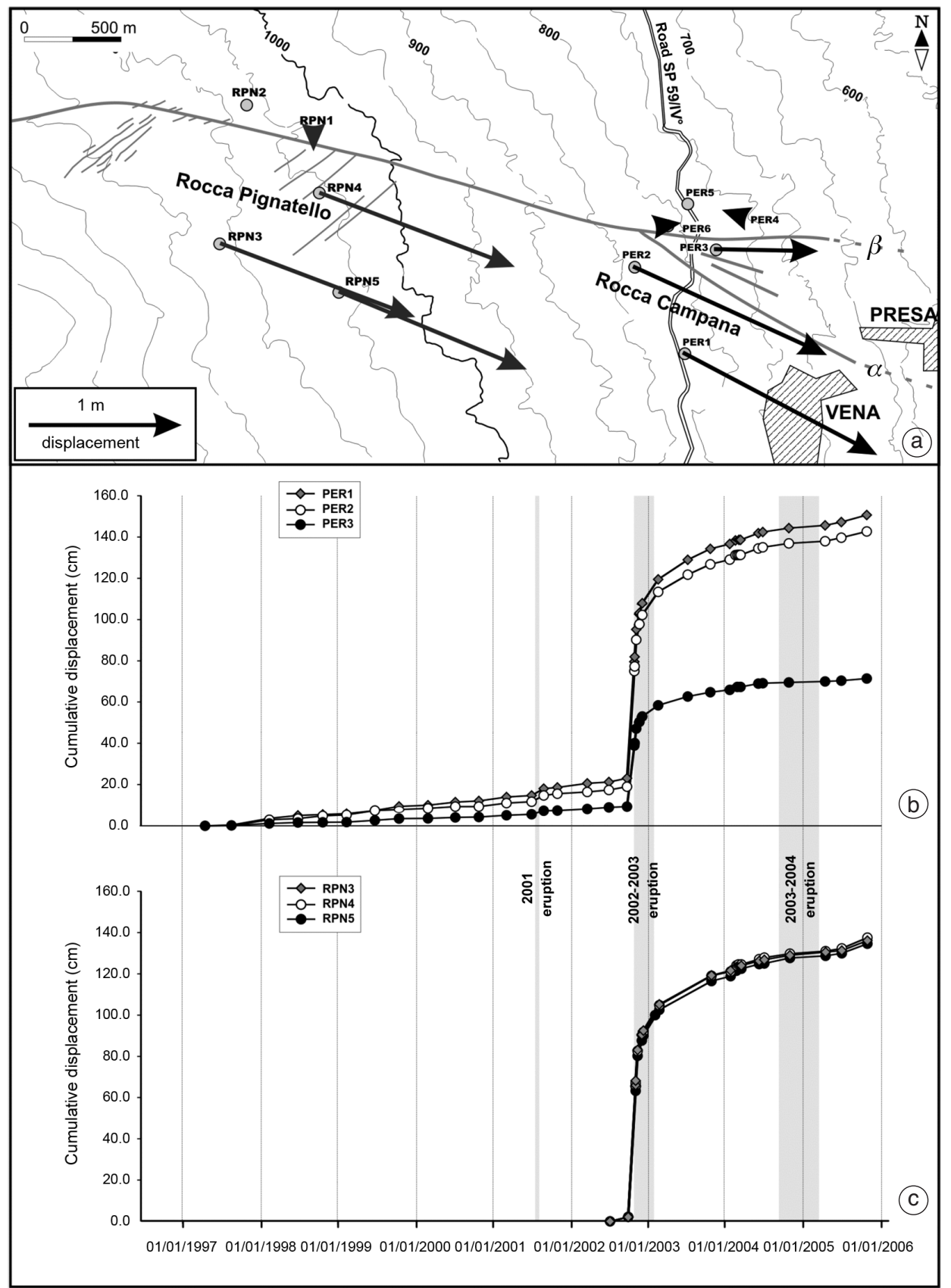

Fig. 5a-c. a) Cumulative horizontal displacements for the two GPS networks: from April 1997 to November 2005 for the RCN network, and from July 2002 to November 2005 for RPN network; b) time evolution of the displacements of some selected benchmarks of the RCN network; c) time evolution of the displacements of some selected benchmarks of the RPN network. 


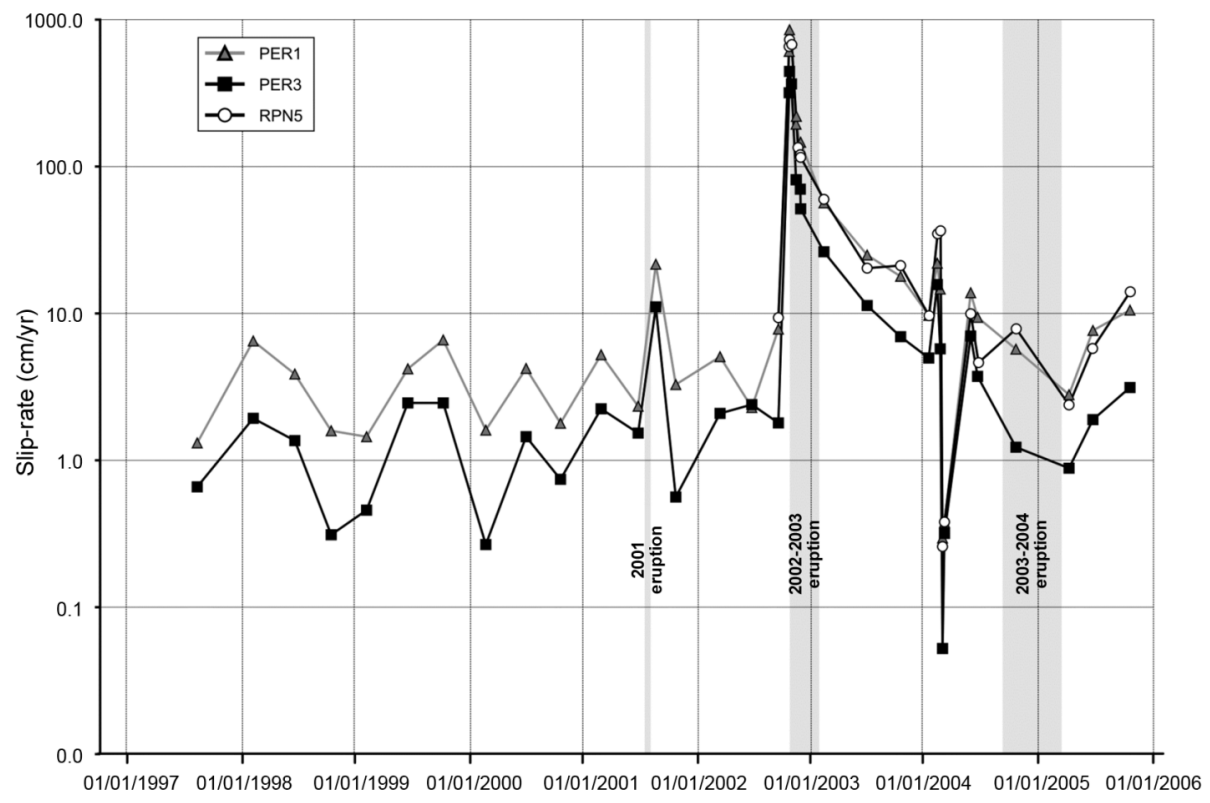

Fig. 6. Time evolution of the slip-rates of some selected GPS benchmarks. $Y$-axis is in logarithmic scale.

iour is visible at PER1, but with less evidence of the reverse motion (fig. 5a).

e) Concerning the slip-rate values, at RCN network, we inferred an averaged slip-rate of about $2.8 \mathrm{~cm} / \mathrm{yr}$ for the splay fault and a slip-rate of $1.1 \mathrm{~cm} / \mathrm{yr}$ for the arm $\beta$ of the main fault (according to Azzaro et al., 2001), until the 20022003 eruption onset (fig. 6). We observed high slip-rate values during the first days of the 20022003 eruption. In the following months the sliprate declined until showing values similar to those observed before the eruption onset. In the last three surveys of the time series, a new increase of the slip-rate was recorded. The same pattern has been observed at the RPN network too.

\subsection{Strain computation}

In order to obtain «averaged» information on the deformation pattern affecting the area, a 2D strain tensor of the geodetic networks was computed. We assumed that the strain field is irrotational, homogeneous and infinitesimal. The strain tensor has been computed by using a least squares algorithm based on the approach suggested by Livieratos (1980), which takes the strain of each baseline as input data into account. An accurate explanation of this method is reported in Azzaro et al. (2001).

In this paper, in order to describe the strain pattern of the investigated areas, we use the following parameters:

$-\Delta$, change in area per unit-area (dilatation), positive for increase in area;

$-\gamma_{2}$, shear across any line parallel to the east axis, positive for right lateral shear;

$-\gamma_{\max }$, shear across the direction having the maximum shear, always positive (maximum shear strain);

$-\varepsilon_{N N}$, change of length per unit-length (strain) in the north direction (positive for extension);

$-\varepsilon_{\mathrm{EE}}$, change of length per unit-length (strain) in the east direction (positive for extension);

$-\varepsilon_{\max }$, maximum principal strain, the change of length per unit-length in the direction 


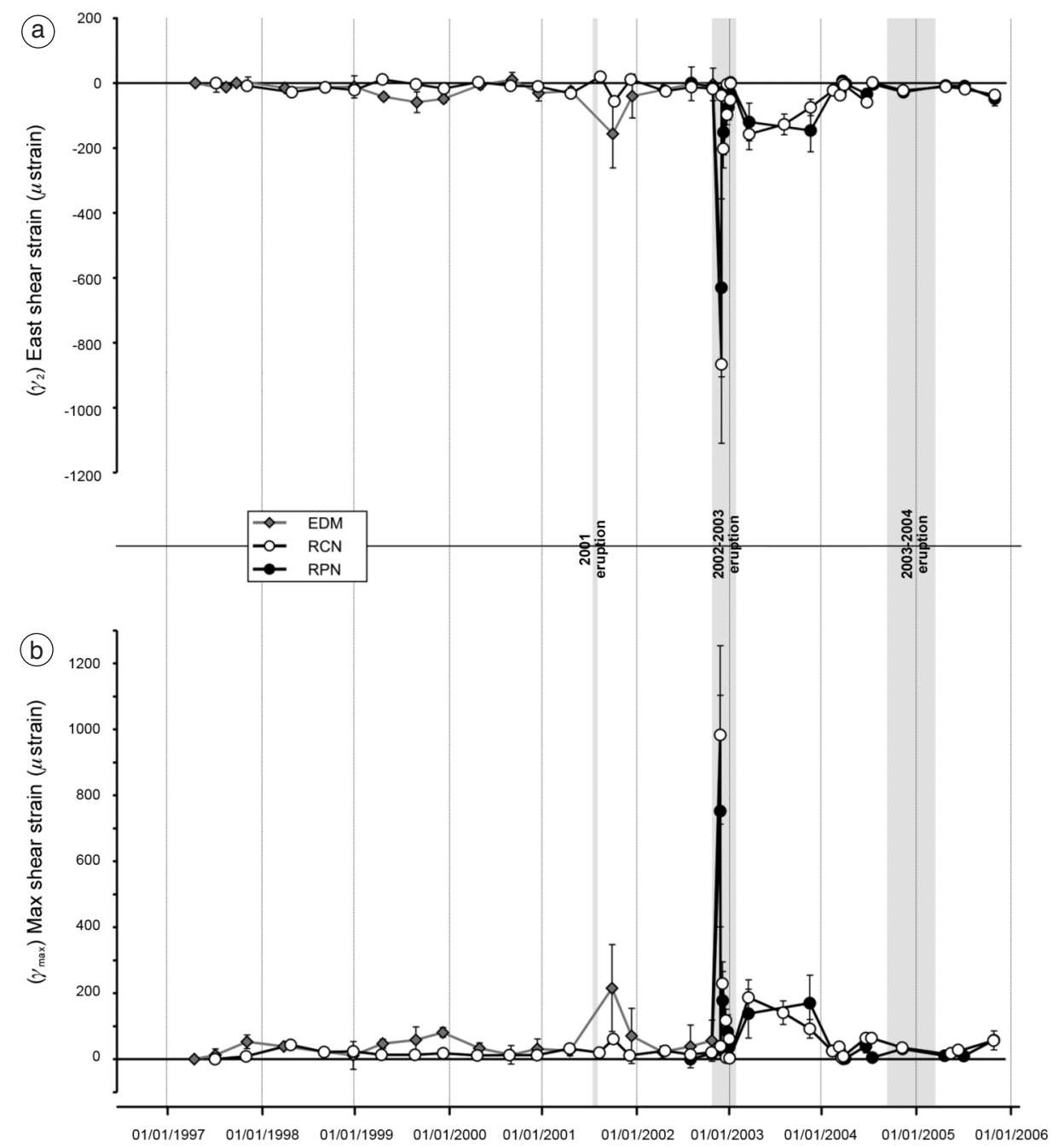

Fig. 7a,b. Time evolution of strain patterns at the geodetic networks: a) east shear strain pattern (strain is assumed to be positive for right-lateral shear); b) maximum shear strain pattern.

having the maximum extension, positive for extension;

$-\varepsilon_{\min }$, minimum principal strain, the change of length per unit-length in the direction having the minimum extension, positive for extension.

Figures $7 \mathrm{a}, \mathrm{b}$ and $8 \mathrm{a}-\mathrm{c}$ report the behaviour of the strain components with time; in fig. 9 we report the rose diagrams relevant to the $\varepsilon_{\max }$ directions.
The evolution of the strain tensor in the investigated areas suggests the following considerations:

a) The strain parameters have small variations (about $40 \mu$ strain) that can be assumed as the «tectonic background» of the fault (figs. $7 \mathrm{a}, \mathrm{b}$ and $8 \mathrm{a}-\mathrm{c})$. The major variations are linked to the 2001 and 2002-2003 eruptions that abruptly change the strain of the fault. 


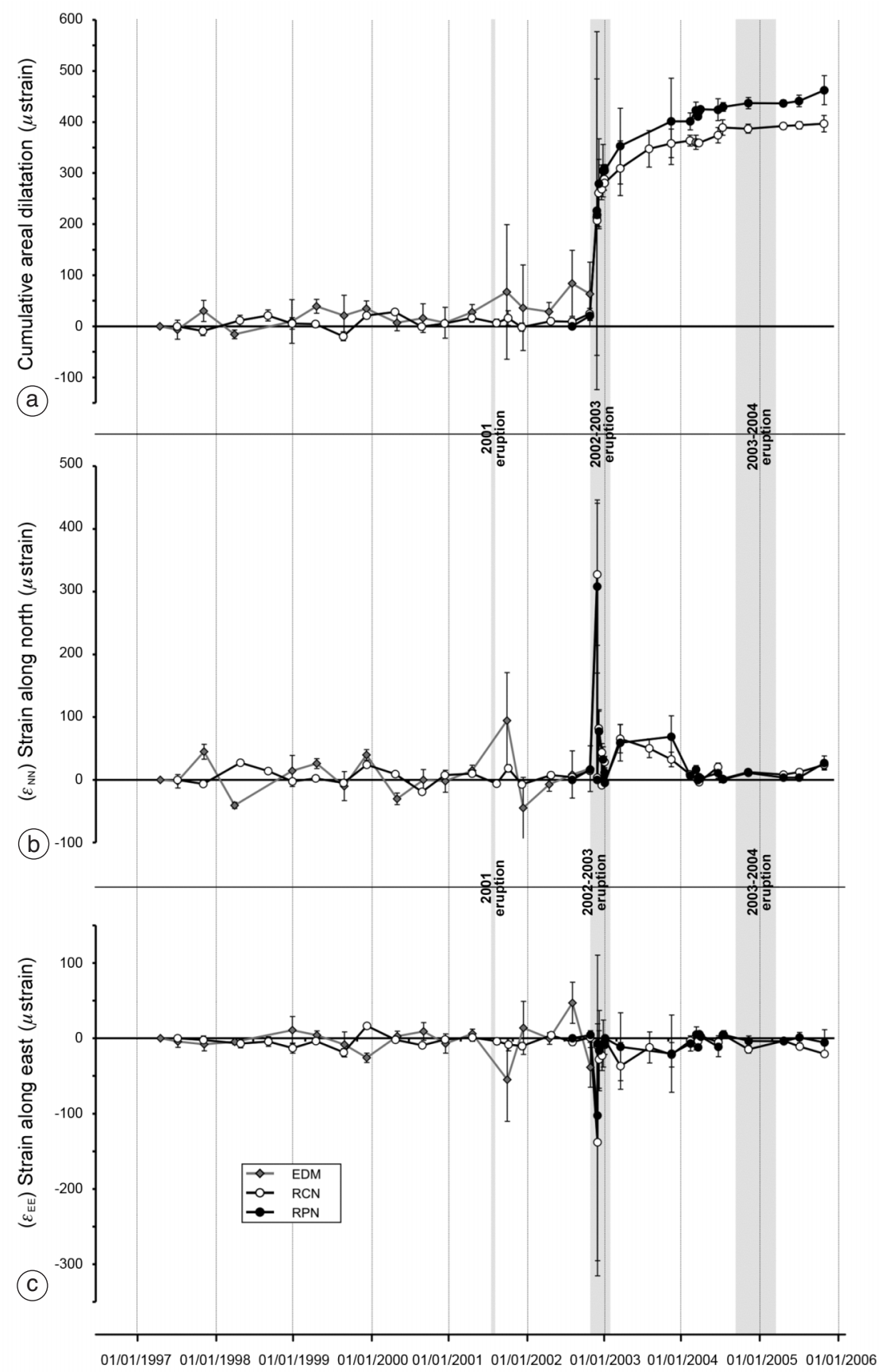

Fig. 8a-c. Time evolution of strain patterns at the geodetic networks: a) cumulative areal dilatation; b) northsouth component of the strain tensor; c) east-west component of the strain tensor. Strain is assumed to be positive for dilatation and for elongation. 


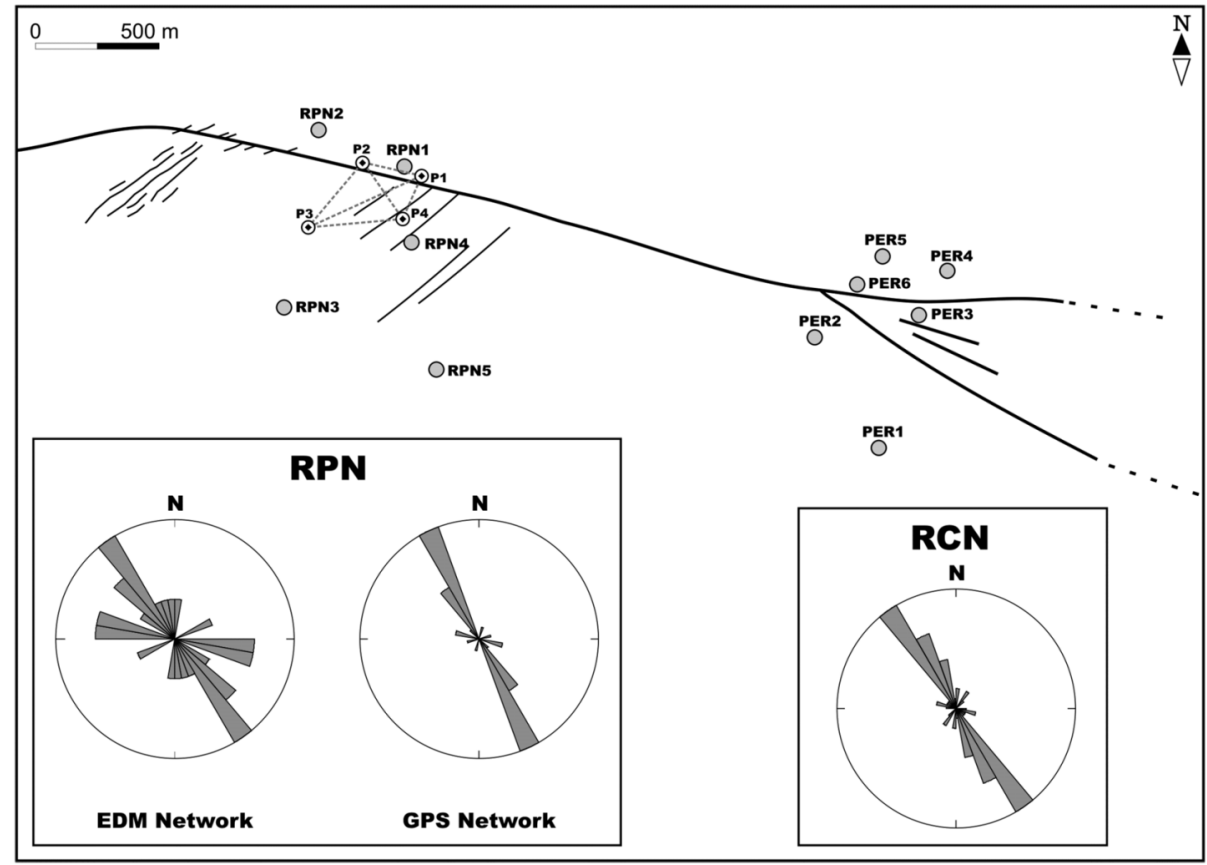

Fig. 9. Rose diagrams of $\varepsilon_{\max }$ directions at geodetic networks. The sector width is $10^{\circ}$.

b) Until July 2001, no significant changes affected the $\Delta$ at RPN and RCN networks (fig. 8a). The «tectonic background» produces a signal of about 30-40 $\mu$ strain. The 2001 and 2002-2003 flank eruptions produces variations in this trend. The largest variation is related to the 2002-2003 eruption onset that results in a positive cumulative variation of about $200 \mu$ strain at both networks. After the end of the eruption, the areal dilatation trend continued with less strain-rate than in the previous period. The 2001 eruption did not produce effects at RCN network, while the RPN one, recorded a positive variation of $40 \mu$ strain, with incertitude so large that prompted us not to consider this value $( \pm 132 \mu$ strain $)$ as valid for further analysis. However, similar differences recorded at both networks in 2001 and 20022003 eruptions (about $45 \mu$ strain) suggest reconsidering the measurement of RPN in 2001 and suggest, in general, that the two areas «respond» differently to an external source: the RPN network dilated more than RCN one. The 2004 eruption did not produce any measurable effect at both networks.

c) Concerning the rose diagrams of the $e_{\max }$ directions (fig. 9), the two networks showed similar strain patterns, with a clear elongation of the areas along the $\mathrm{N} 170^{\circ} \mathrm{E}-\mathrm{N} 10^{\circ} \mathrm{W}$ directions. The rose diagram for the EDM network shows a more scattered pattern; this could be due to the different precision between the EDM and GPS measurements.

\section{Discussion and conclusions}

Mt. Etna is characterised by a complex geodynamic setting resulting from the combination of regional tectonic and flank instability (Bousquet and Lanzafame, 2004). The eastern flank of the volcano is affected by a continuous ESE seaward sliding due to the interrelationship between gravity instability and magma intrusion (Borgia et al., 1992; Lo Giudice and Rasà, 
1992; McGuire et al., 1996; Montalto et al., 1996; Rust and Neri, 1996; Tibaldi and Groppelli, 2002; Bonforte and Puglisi, 2003). Although the models proposed to explain the origin of this sliding are quite different regarding the origin of the movements and the southern and the bottom boundaries of the moving block, they all agree in identifying the Pernicana Fault as the northern boundary of the unstable sector.

The left-lateral behaviour of the Pernicana Fault is the most evident feature from geological observations (Azzaro et al., 1998; Acocella et al., 2003). The eastward propagation of the Pernicana Fault was identified for the first time by Azzaro et al. (1998), who evidenced the presence of several splay segments that gradually partition the fault motion close to Vena and Presa villages (fig. 2); during the 2002-2003 Mt. Etna eruption, the huge ground fracturing phenomena allowed to identify the development and the kinematic of the fault down to the Ionian coast (Neri et al., 2004).

In the investigated area, the fault is characterized by aseismic creep with striking evidence of activity revealed by continuous left-lateral displacements having an average creep-rate of a) $2 \mathrm{~cm} / \mathrm{yr}$, reconstructed over the past 150 years as estimated on man-made structures (Rasà et al., 1996); b) $2.8 \mathrm{~cm} / \mathrm{yr}$ based on geodetic estimations for the 1997-1999 time interval (Azzaro et al., 2001); c) $2.7 \mathrm{~cm} / \mathrm{yr}$ as estimated on geological observations for the Latest Pleistocene-Holocene (Tibaldi and Groppelli, 2002).

This paper analyses the ground deformation occurring on the eastern part of the Pernicana Fault (near the villages of Vena and Presa) from 1997 to 2005 by using GPS and EDM techniques. In order to adequately detect the fast and continuous ground deformation of the Pernicana Fault, the geodetic surveys have been performed at least three times per year. This high temporal detail allows us to characterize the active fault segments in terms of kinematics and behaviour.

In agreement with geological evidence, ground deformation measurements have detected a continuous fault movement. In particular, we inferred an averaged slip-rate of about 2.8 $\mathrm{cm} / \mathrm{yr}$ for the splay fault and a slip-rate of 1.1 $\mathrm{cm} / \mathrm{yr}$ for the arm $\beta$ of the main fault until the
2002-03 eruption onset, accordingly with the values proposed by Azzaro et al. (2001) and Tibaldi and Groppelli (2002). By projecting the three components of the slip-rate value along the Line Of Sight (LOS) of the ERS1/2 SAR sensors (in ascending orbits geometry), the GPS data also agreed with the value detected by Lundgren et al. (2004), who measured about 1 $\mathrm{cm} / \mathrm{yr}$ in LOS for the 1992-2001 period, across the eastern part of the Pernicana Fault. In the first days of the 2002-2003 eruption we observed high slip-rate values. In the following months the slip-rate declined until showing values similar to those observed before the eruption onset.

The ground deformation data clearly evidenced that the deformation is transferred entirely $E$-wards by the main fault at RPN area and by the splay fault at RCN one, with the same slip-rates (fig. 1a,b). In this last area, the partition effects played by the splay fault resulted very important, accommodating more than twice the displacement on the $E$-ward prolongation of the $\operatorname{arm} \beta$ of the main fault. However, the accelerations of the two fault segments are strongly correlated (fig. 6).

Strain tensor analysis evidenced that RPN network dilated more than $\mathrm{RCN}$ one. A relative reverse motion between the two sides of the Pernicana fault system could be generated from the decoupling between the hanging-wall and foot-wall during the inflation/deflation phases of the volcano, as measured, for instance, by the Mt. Etna GPS network in 1994 (Puglisi et al., 2001). In such a framework, the different reverse kinematics measured at the two areas can be originated from the different «response» to external sources of the two areas in terms of $\Delta$, which, in turn, could be a function of the geometric assessment of the main features in these areas. In particular, the change of the strike direction of the Pernicana fault system at $\mathrm{RCN}$ produces a local convergence between it and the average strike-slip direction of the sliding of the Mt. Etna eastern flank.

Finally, this work confirms that small geodetic networks may contribute to defining the dynamics characterising active faults such as the Pernicana one, as proposed in Azzaro et al. (2001). Furthermore, looking at the key role 
played by the Pernicana Fault in the flank dynamics of Mt. Etna, the positive results of this experience suggest improvements in planning future monitoring ground deformation in this area. The evolution of one (or both) of these two networks towards systems based on permanent GPS stations and/or the installation of other GPS networks, W-ward of RPN area (along the Pernicana Fault trace) and/or E-ward of $\mathrm{RCN}$ area (along the splay fault trace) could allow a better monitoring both in space and time of this fault system.

\section{Acknowledgements}

We are grateful to two anonymous reviewers for their suggestions and for their fruitful comments on the paper.

\section{REFERENCES}

Acocella, V., B. Behncke, M. Neri and S. D'Amico (2003): Link between major flank slip and eruptions at Mt. Etna (Italy), Geophys. Res. Lett., 30, doi: 10.1029/ 2003 GL018642.

Andronico, D., S. Branca, S. Calvari, M.B. Burton, T. Caltabiano, R.A. Corsaro, P. Del Carlo, G. Garfì, L. Lodato, L. Miraglia, F. Murè, M. Neri, E. PecoRa, M. Pompilio, G. Salerno and L. SPampinato (2005): A multi-disciplinary study of the 2002-2003 Etna eruption: insights into a complex plumbing system, Bull. Volcanol., 67, 314-330.

Azzaro, R., L. Ferreli, A.L. Michetti, L. Serva and E. VITTORI (1998): Environmental hazard of capable faults: the case of the Pernicana Fault (Mt. Etna, Sici1y), Nat. Hazards, 17, 147-162.

Azzaro, R., M. Mattia and G. Puglisi (2001): Fault creep and kinematics of the eastern segment of the Pernicana Fault (Mt. Etna, Sicily) derived from geodetic observations and their tectonic significance, Tectonophysics, 333, 401-415.

Barberi, G., O. Cocina, V. Maiolino, C. Musumeci and E. Privitera (2004): Insight into Mt. Etna (Italy) kinematics during 2002-2003 eruption as inferred by seismic stress and strain tensors inversion, Geophys. Res. Lett., 31, doi: 10.1029/2004GL020918.

BeHNCKE, B. and M. NeRI (2003): The July-August 2001 eruption of Mt. Etna (Sicily), Bull. Volcanol., 65, 461476.

Bonforte, A. and G. Puglisi (2003): Magma uprising and flank dynamics on Mount Etna volcano, studied using GPS data (1994-1995), J. Geophys. Res., 108, doi: 10.1029/2002JB001845.

Borgia, A., L. Ferrari and G. Pasquarè (1992): Importance of gravitational spreading in the tectonic and vol- canic evolution of Mount Etna, Nature, 357, 231-235.

BousQuET, J.C. and G. LANZAFAME (2004): The tectonics and geodynamics of Mt. Etna: synthesis and interpretation of geological and geophysical data, in Mt. Etna Volcano Laboratory, edited by A. Bonaccorso, S. CALVARI, M. Coltelli, C. Del Negro and F. Falsaperla, Am. Geophys. Un., Geophys. Monogr. Ser, 143, 29-47.

Burton, M.R., M. Neri, D. Andronico, S. Branca, T. Caltabiano, S. Calvari, R.A. Corsaro, P. Del Carlo, G. Lanzafame, L. Lodato, L. Miraglia, G. SaLERNO and L. SPAMPINATO (2005): Etna 2004-2005: An archetype for geodynamically-controlled effusive eruptions, Geophys. Res. Lett., 32, doi: 10.1029/ 2005 GL022527.

INGV - CT RESEARCH STAFF (2001): Multidisciplinary approach yields insight into Mt. Etna eruption, Eos, Trans. Am. Geophys. Un., 82 (50), 653-656.

Livieratos, E. (1980): Crustal strains using geodetic methods, Quaterniones Geod., 3, 191-211.

Lo GIUDICE, E. and R. RASÀ (1992): Very shallow earthquakes and brittle deformation in active volcanic areas: the Etnean region as an example, Tectonophysics, 202, 257-268.

Lundgren, P., F. Casu, M. Manzo, A. Pepe, P. Berardino, E. SANSOSTI and R. LANARI (2004): Gravity and magma induced spreading of Mount Etna volcano revealed by satellite radar interferometry, Geophys. Res. Lett., 31, doi: 10.1029/2003GL018736.

McGuire, W.J., J.L. Moss, S.J. SAundres and I.S. StewART (1996): Dyke-induced rifting and edifice instability at Mount Etna, in Etna: Fifteen Years On, edited by P.J. Gravestock and W.J. McGuIRE, Cheltenham and Gloucester Special Publ., 20-24.

Montalto, A., S. Vinciguerra, S.B.C. Menza and G. PATANE (1996): Recent seismicity of Mount Etna: implications for flank instability, in Volcano Instability on the Earth and Other Planets, edited by W.J. McGuIRE, A.P. Jones and J. NEUBERG, 169-177.

Neri, M., V. ACOCELla and B. BeHnCKe (2004): The role of the Pernicana fault system in the spreading of Mt. Etna (Italy) during the 2002-2003 eruption, Bull. Volcanol., 66, 417-430, doi: 10.1007/s00445-003-0322-x.

Obrizzo, F., F. Pingue, C. Troise and G. De Natale (2001): Coseismic displacements and creeping along Pernicana Fault (Mt. Etna ) in the last seventeen years: a detailed study of a structure on a volcano, J. Volcanol. Geotherm. Res., 109, 109-131.

PRESCOTT, W.H. (1981): The determination of displacement fields from geodetic data along strike-slip faults, $J$. Geophys. Res., 81, 3518-3524.

Puglisi, G., M. Bonaccorso, A. Bonforte, O. Campisi, O. Consoli, S.R. Maugeri, G. Nunnari, B. Puglisi, M. Rossi and R. VElardita (1998): 1993-1995 GPS measurements on Mt. Etna: improvements in network configuration and surveying techniques, Acta Vulcanol., 10, 158-169.

Puglisi, G., A. Bonforte and S.R. Maugeri (2001): Ground deformation patterns on Mt. Etna, between 1992 and 1994, inferred from GPS data, Bull. Volcanol., 62, 371-384.

RAsÀ, R., R. AZZARO and O. LEONARDI (1996): Aseismic creep on faults and flank instability at Mt. Etna volcano, Sicily, in Volcano Instability on the Earth and 
Other Planets, edited by W.J. McGuIRE, A.P. JONES and J. NEUBERG, 179-192.

Rust, D. and M. NERI (1996): The boundaries of large-scale collapse on the flanks of Mt. Etna, Sicily, Volcano Instability on the Earth and Other Planets, edited by W.J. McGuire, A.P. Jones and J. NeuberG, 193-208.

Tibaldi, A. and G. GRopPELLI (2002): Volcano-tectonic ac- tivity along structures of the unstable NE flank of Mt Etna (Italy) and their possible origin, J. Volcanol. Geotherm. Res., 115, 277-302.

(received February 2, 2006; accepted August 1, 2006) 